\title{
Desempenho produtivo de bovinos Nelore de diferentes classes sexuais alimentados com dietas contendo dois níveis de oferta de concentrado ${ }^{1}$
}

\author{
Pedro Veiga Rodrigues Paulino ${ }^{2 *}$, Sebastião de Campos Valadares Filho ${ }^{3}$, Edenio Detmann ${ }^{3}$ \\ Rilene Ferreira Diniz Valadares ${ }^{4}$, Mozart Alves Fonseca ${ }^{5}$, Robson Magno Liberal Véras ${ }^{2}$, \\ Diogo Moura Oliveira ${ }^{6}$
}

\author{
${ }^{1}$ Pesquisa financiada pelo CNPq. \\ 2 Programa de Pós-graduação em Zootecnia - UFV. \\ ${ }^{3}$ DZO/UFV, Viçosa, MG. \\ ${ }^{4}$ DVT/UFV, Viçosa, MG. \\ ${ }^{5}$ Graduando em Agronomia - UFV. Bolsista de Iniciação Científica PIBIC/CNPq \\ ${ }^{6}$ Graduando em Medicina Veterinária - UFV. Bolsista de Iniciação Científica CNPq.
}

RESUMO - Objetivou-se avaliar os efeitos de classe sexual e nível de oferta de concentrado sobre o desempenho, o consumo e a digestibilidade dos nutrientes em bovinos Nelore. Trinta e cinco animais, 12 machos inteiros, 11 machos castrados e 12 fêmeas, provenientes de um mesmo grupo contemporâneo, foram distribuídos aleatoriamente a dois tratamentos, correspondentes aos níveis de oferta de concentrado, 0,6 e 1,2\% do peso corporal, respectivamente. Os animais foram alimentados individualmente durante 112 dias, sendo abatidos ao final do experimento, com um grupo referência abatido ao início. Os machos inteiros foram mais eficientes, pois apresentaram maior peso final e de corpo vazio, como resultado da maior taxa de crescimento em relação às fêmeas, ficando os machos castrados em posição intermediária. Os consumos relativos de matéria seca e de todos os demais nutrientes foram superiores nas fêmeas em relação aos machos inteiros, de modo que os castrados apresentaram valores intermediários. As digestibilidades, à exceção do extrato etéreo, não foram afetadas pela classe sexual. As digestibilidades da matéria seca e matéria orgânica foram superiores para a dieta com nível de oferta de concentrado de 1,2\% do PV. Classe sexual afetou o crescimento e a capacidade de consumo dos animais, porém não teve efeito sobre a digestibilidade dos nutrientes da dieta. Níveis de oferta de concentrado de 0,6 e 1,2\% do PV não foram suficientes para promover diferenças no desempenho de bovinos Nelore independentemente de classe sexual.

Palavras-chave: bovinos de corte, crescimento, consumo, digestibilidade

\section{Productive performance of Nellore cattle of different gender fed diets containing two levels of concentrate allowance}

\begin{abstract}
The objective of this work was to evaluate the effects of sex class and concentrate allowance level on performance and digestibility of the nutrients in Nellore cattle. Thirty five animals were used, 12 young bulls, 11 steers and 12 heifers, from the same contemporary group, were randomly allotted into two treatments: concentrate allowance levels of 0.6 and $1.2 \% \mathrm{BW}$, respectively. The animals were individually fed during 112 days, and slaughtered at the end of the trial with a reference group slaughtered at the beginning of the trial. The young bulls were more efficient and had heavier body weight (BW) and empty body weight (EBW), as a result of their increased growth rate in relation to the heifers, with the steers presenting intermediate values. The relative intakes (\% BW) of dry matter and of all other nutrients were superior in the heifers in relations to the young bulls, while the steers showed intermediate values. The digestibilities, except EE, were unaffected by sexual class. The digestibilities of dry matter and organic matter were higher for the diet with concentrate allowance of $1.2 \% \mathrm{BW}$. Sexual class affected the growth and the intake capacity of the animals, however with no effect on the digestibility of the nutrients of the diet. Concentrate allowance levels of 0.6 and $1.2 \% \mathrm{BW}$ were not sufficient to elicit difference in the performance of Nellore cattle, independently of sex class.
\end{abstract}

Key Words: beef cattle, growth, intake, digestibility

Este artigo foi recebido em 12/2/2007 e aprovado em 20/11/2007.

Correspondências devem ser enviadas para pveiga@ufv.br.

* Endereço atual: Departamento de Zootecnia - UFV. 


\section{Introdução}

Em qualquer empreendimento agropecuário que tem como principal fonte de renda algum tipo de commodity agrícola, eventos cíclicos de preço ao longo do tempo são uma realidade e fazem parte do processo produtivo, incluindo a produção de carne bovina. Quando se analisa a história da pecuária de corte brasileira, percebe-se que, durante sua evolução, diversos momentos de dificuldade ocorreram (Polaquini et al., 2006), ocasionados por uma combinação de circunstâncias, na maioria das vezes, fora do alcance dos pecuaristas, técnicos e pesquisadores envolvidos com a atividade. Assim, a alocação dos recursos destinados à produção e à organização do capital produtivo passam a ter como foco a maximização dos resultados econômicos da atividade (Polaquini et al., 2006).

A manipulação da dieta e o uso de animais de diferentes condições sexuais representam uma ferramenta disponível ao pecuarista, de forma a obter uma associação que lhe traga maior eficiência produtiva e econômica, dentro de sua realidade de produção. São recursos cuja manipulação e controle estão ao alcance do manejador do sistema de produção, sendo a magnitude dos seus impactos sobre esse sistema dependente do mercado e do nível tecnológico empregado na exploração pecuária.

A dieta em si pode afetar o consumo e as digestibilidades dos nutrientes e, como consequência imediata, o desempenho dos animais, bem como a composição corporal e da carcaça (Fortin et al., 1980). O uso de concentrados na dieta de bovinos de corte, seja em confinamento, ou a pasto, tem sido empregado como uma forma de melhorar o desempenho dos animais, com concomitante redução no tempo de abate ou na idade à primeira cria, o que pode proporcionar maior eficiência de produção do sistema como um todo. Entretanto, em função do nível de oferta de concentrado utilizado, alterações no consumo, na digestibilidade dos nutrientes e nos parâmetros de desempenho passam a ocorrer. Os resultados obtidos pela pesquisa agropecuária brasileira em relação ao efeito de níveis de concentrado sobre o desempenho, o consumo e a digestibilidade dos nutrientes da dieta em bovinos de corte mostram-se variáveis, sendo verificados efeitos positivos, negativos ou nulos (Silva et al., 2002; Pereira et al., 2006).

Por outro lado, o efeito da classe sexual tem se mostrado altamente determinante de diferenças no crescimento e nas taxas de deposição dos diferentes tecidos corporais e da carcaça (Berg \& Butterfield, 1976). Machos inteiros apresentam taxa de crescimento em torno de 10 a $20 \%$ superior aos machos castrados e às fêmeas, desde que mantidos em condições que lhes permitam expressar seu potencial de crescimento (Pádua et al., 2004). No entanto, muito pouco se conhece sobre o efeito de classe sexual, bem como de sua interação com dietas de maior ou menor densidade energética, sobre o desempenho e os parâmetros de consumo e digestibilidade dos nutrientes, particularmente na raça Nelore, que compõe grande parte do rebanho nacional.

Nesse sentido, realizou-se este trabalho objetivando estudar os efeitos de classe sexual e nível de oferta de concentrado sobre os parâmetros de desempenho produtivo de bovinos Nelore.

\section{Material e Métodos}

O experimento foi realizado no confinamento experimental do Laboratório Animal do Departamento de Zootecnia da Universidade Federal de Viçosa, no período de outubro de 2004 a janeiro de 2005.

Foram utilizados 35 animais da raça Nelore, sendo 12 machos inteiros, 11 machos castrados e 12 fêmeas. Os animais pertenciam a um mesmo rebanho comercial, utilizado em experimento prévio, no qual foram alimentados com uma mesma dieta $(11,80 \%$ de proteína bruta - PB e $56,90 \%$ de nutrientes digestíveis totais - NDT) durante 77 dias (Paulino et al., 2005). Imediatamente após o término deste experimento, 11 animais (quatro machos inteiros, três machos castrados e quatro fêmeas) foram abatidos, de forma a comporem o grupo referência, sendo utilizados para estimação da composição inicial do corpo vazio e da carcaça dos demais animais. O abate foi realizado após jejum de sólidos de 16 horas.

Os animais remanescentes permaneceram alojados no confinamento experimental, em baias individuais, com dimensões de 1,8 $\mathrm{m}$ de largura por $18,8 \mathrm{~m}$ de comprimento, totalizando $33,84 \mathrm{~m}^{2}$. Desse total, $11,88 \mathrm{~m}^{2}(1,8 \times 6,6 \mathrm{~m}) \mathrm{eram}$ de piso de concreto e cobertos com telha de amianto. Cada baia era provida de comedouro $(1,6 \mathrm{~m})$ e bebedouro de concreto individuais.

O delineamento experimental utilizado foi o inteiramente casualizado, em esquema fatorial $3 \times 2$, respectivamente, três classes sexuais (machos inteiros, machos castrados e fêmeas) e dois níveis de oferta de concentrado ( 0,6 e $1,2 \%$ do peso corporal - PC), compondo, portanto, seis tratamentos.

No início do experimento, os animais estavam com idade média de 24 meses, apresentando pesos corporais médios de $341,7 \pm 4,5 ; 321,0 \pm 7,0$ e $296,4 \pm 6,3 \mathrm{~kg}$, respectivamente, para os machos inteiros, machos castrados e fêmeas.

Os animais foram adaptados às dietas experimentais formuladas de forma a serem isonitrogenadas, utilizando-se 
silagem de milho como alimento volumoso - durante uma semana. Os concentrados experimentais (Tabela 1) foram formulados com milho moído fino, farelo de algodão $42 \%$, uréia:sulfato de amônio (9:1), calcário calcítico, cloreto de sódio e mistura mineral comercial.

O experimento, com duração de 112 dias, foi subdivido em quatro períodos experimentais de 28 dias cada. Os alimentos (volumoso + concentrado) foram fornecidos duas vezes ao dia (6h30 e 15h30), com aproximadamente $60 \%$ da quantidade diária fornecida pela manhã e os $40 \%$ restantes no período da tarde. A quantidade de concentrado fornecida foi ajustada a cada 28 dias, quando os animais foram pesados, sempre após jejum de sólidos de 16 horas. $\mathrm{O}$ alimento volumoso (silagem de milho) foi pesado diariamente e ofertado à vontade. Desta forma, a relação volumoso:concentrado da dieta variou ao longo do experimento. Tomando-se as quantidades ofertadas de matéria seca (MS) da silagem de milho e dos concentrados experimentais, calcularam-se as relações volumoso-concentrado ao longo do experimento para os tratamentos com oferta de concentrado fixa em 0,6 ou $1,2 \%$ PC, respectivamente, observando-se valores de 72,5:27,5 e 46,7:53,3; 74,7:25,3 e $50,0: 50 ; 0,80,5: 19,5$ e $62,8: 37,2 ;$ e $78,6: 21,4$ e $59,7: 40,3$, respectivamente, no primeiro, segundo, terceiro e quarto períodos experimentais. O procedimento de fixar somente $\mathrm{o}$ concentrado e manter flutuante a quantidade de volumoso ofertado não teve impactos sobre a análise geral do experimento, uma vez que os consumos foram controlados e mensurados semanalmente.

As sobras foram coletadas diariamente, pesadas e amostradas, por animal, sendo acondicionadas em sacos plásticos devidamente identificados. Foram mantidas em freezer a $-20^{\circ} \mathrm{C}$ e, após cada semana, descongeladas e homogeneizadas, retirando-se uma sub-amostra, que foi pesada, pré-seca em estufa de ventilação forçada a $65^{\circ} \mathrm{C}$ por 72 horas, processada em moinho com peneira com malha de $1 \mathrm{~mm}$ e acondicionada em recipiente plástico identificado por animal. Amostras de quatro semanas consecutivas, já moídas, foram utilizadas para obtenção de uma amostra composta de sobras, com base no peso seco ao ar, por animal, por período de 28 dias. Nesse sentido, para cada animal, obtiveram-se quatro amostras compostas de sobras, que foram armazenadas em local fresco e arejado para posteriores análises laboratoriais.

Amostras da silagem de milho também foram obtidas diariamente, compostas por semana, pré-secas, moídas e armazenadas. Dessa forma, o volumoso utilizado foi analisado semanalmente. Amostras dos ingredientes dos concentrados (milho e farelo de algodão) foram coletados a
Tabela 1 - Composição em ingredientes dos concentrados (\%MS), em função dos níveis de oferta de concentrado

\begin{tabular}{lcc}
\hline Ingrediente (\%) & $\begin{array}{c}\text { Nível de oferta de concentrado } \\
(\% \text { do PV) }\end{array}$ \\
\cline { 2 - 3 } & 0,6 & 1,2 \\
\hline Milho moído fino & 58,40 & 82,84 \\
Farelo de algodão 42\% & 33,57 & 13,13 \\
Uréia/sulfato de amônio & 3,35 & 1,68 \\
Calcário calcítico & 2,23 & 1,12 \\
Cloreto de sódio & 1,23 & 0,62 \\
Mistura mineral $^{1}$ & 1,23 & 0,62 \\
\hline
\end{tabular}

${ }^{1}$ Composição da mistura mineral, por kg do produto: Ca, $240 \mathrm{~g} ; \mathrm{P}, 174 \mathrm{~g}$ Co, 100 mg; Cu, 1.250 mg; Fe, 1.795 mg; F (máx.), 1.740 mg; I, 90 mg; $\mathrm{Mn}, 2.000 \mathrm{mg}$; Zn, $5.270 \mathrm{mg}$; Se, $15 \mathrm{mg}$; veículo q.s.p., $1.000 \mathrm{~g}$.

cada partida, totalizando três amostras de cada ingrediente ao longo do experimento.

Ensaios de digestibilidade foram realizados em cada período experimental, sempre em seu terço médio, ou seja, ao final da segunda semana de cada período de 28 dias. Durante os ensaios, foram coletadas amostras de fezes de cada animal em dois dias consecutivos, diretamente no piso das baias e imediatamente após a defecação. No primeiro dia, as fezes foram coletadas no período da manhã e no dia subseqüente, no período da tarde. As amostras de fezes foram acondicionadas em pratos de alumínio e levadas à estufa de ventilação forçada a $65^{\circ} \mathrm{C}$, durante 72 horas. Depois de secas, foram processadas em moinho com peneira de malha de $1 \mathrm{~mm}$ e, em seguida, acondicionadas em recipientes de plástico. Para cada animal, e por período, foram obtidas duas amostras de fezes (manhã e tarde), que foram proporcionalmente homogeneizadas, depois de secas e moídas, formando amostra composta. Desta forma, ao longo de todo o período experimental, obtiveram-se quatro amostras compostas de fezes para cada animal.

A excreção fecal foi estimada a partir da técnica do indicador interno, conforme Cochran et al. (1986), utilizando-se a fibra em detergente ácido indigestível (FDAi). Os teores de FDAi nas amostras de fezes, sobras e alimentos fornecidos (silagem de milho e concentrados) foram obtidos como o resíduo resultante após tratamento das amostras, depois de incubadas in situ por um período de 144 horas, com detergente ácido (FDA). Para a incubação in situ, empregou-se o sistema $\mathrm{ANKOM}^{\circledR}$, com modificação do saquinho utilizado, conforme descrito posteriormente.

Como foram realizados quatro ensaios de digestibilidade ao longo do experimento, obteve-se a média das digestibilidades, as quais foram submetidas às devidas análises estatísticas.

As amostras da silagem de milho e dos ingredientes dos concentrados (milho moído fino e farelo de algodão), das 
sobras e das fezes foram analisadas quanto aos seus teores de MS, matéria mineral (MM), nitrogênio total e extrato etéreo (EE), segundo as recomendações de Silva \& Queiroz (2002). A matéria orgânica (MO) foi obtida como 100 - MM e o teor de proteína bruta $(\mathrm{PB})$, a partir do produto do $\mathrm{N}$ total e o fator 6,25. Os teores de fibra em detergente neutro (FDN) e nitrogênio insolúvel em detergente neutro (NIDN) foram obtidos de acordo com os protocolos descritos por Van Soest et al. (1991) e Licitra et al. (1996). Os teores de fibra em detergente ácido, nitrogênio insolúvel em detergente ácido (NIDA) e lignina (LIG) (ácido sulfúrico 72\%) foram obtidos segundo Van Soest \& Robertson (1980) e Licitra et al. (1996). Utilizou-se o sistema ANKOM ${ }^{\circledR}$ para as avaliações de FDN e FDA, com modificação do saquinho utilizado $(5,0 \times 5,0 \mathrm{~cm}$, porosidade de $100 \mu \mathrm{m})$, que foi confeccionado utilizando-se tecido não-tecido (TNT - densidade: $100 \mathrm{~g} / \mathrm{m}^{2}$ ). Alpha-amilase estável ao calor foi empregada nas análises de FDN, cujas amostras de alimentos, sobras e fezes não foram corrigidas para cinzas.

Os carboidrados não-fibrosos (CNF) foram calculados de acordo com o NRC (2001), como: CNF (\%) $=100-(\%$ PB $+\% \mathrm{EE}+\%$ cinzas $+(\% \mathrm{FDN}-\% \mathrm{PIDN}))$. Para os concentrados, em virtude da presença de uréia em suas constituições, o teor de CNF foi calculado como proposto por Hall (2000), sendo $\mathrm{CNF}=100-((\% \mathrm{~PB}-\% \mathrm{~PB}$ derivada da uréia $+\%$ de uréia) $+\% \mathrm{FDNp}+\% \mathrm{EE}+\%$ cinzas $)$.

A densidade energética das dietas experimentais, expressa em termos de nutrientes digestíveis totais, foi determinada a partir da fórmula recomendada pelo NRC (2001): NDT $(\%)=\mathrm{PBD}+2,25 \times \mathrm{EED}+\mathrm{CNFD}+\mathrm{FDNpD}$, em que PBD, EED, CNFD e FDNpD significam, respectivamente, proteína bruta digestível, extrato etéreo digestível, carboidratos não-fibrosos digestíveis e fibra em detergente neutro (isenta de proteína) digestível, cujos coeficientes de digestibilidade foram obtidos neste experimento. A concentração de energia digestível (ED) das dietas foi obtida pela equação proposta pelo NRC (2001): ED (Mcal/kg MS) $=5,6 \times \mathrm{PBD}+9,4 \times \mathrm{EED}+4,2 \times \mathrm{FDNpD}+4,2 \times \mathrm{CNFD}$. Já as concentrações de energia metabolizável (EM) foram consideradas como sendo $82 \%$ da ED (NRC, 2000).

Todos os animais foram abatidos ao término do experimento. No entanto, em virtude de limitações físicas das instalações do abatedouro utilizado, foi possível abater somente seis animais em cada dia de abate, sendo 1 animal de cada tratamento por dia de abate. Como a pesagem das carcaças foi realizada um dia após o abate, em virtude do tempo transcorrido para resfriamento, foram necessários seis dias alternados para que todos os animais fossem abatidos. Os animais foram pesados, após jejum de sólidos de 16 horas, e abatidos em seguida, por concussão cerebral, seguida de secção da veia jugular, conforme resolução 714 de 2002 do Conselho Federal de Medicina Veterinária (CFMV). O sangue foi recolhido em recipiente plástico e pesado. Todas as partes constituintes do corpo animal (cabeça, patas, cauda, couro e aparelho gastrintestinal: rúmen, retículo, omaso, abomaso, intestino delgado, intestino grosso; órgãos internos: pulmões, rins, coração, baço, fígado, gordura interna total, mesentério, língua, diafragma e aparas: esôfago, traquéia, laringe e aparelho reprodutivo; e meias-carcaças esquerda e direita) foram pesadas. $\mathrm{O}$ trato gastrintestinal foi devidamente esvaziado e lavado previamente à sua pesagem.

O peso de corpo vazio (PCVZ) de cada animal foi obtido pelo somatório de todas as partes constituintes do corpo descritas acima, mais o sangue. Para obtenção do peso de corpo vazio inicial dos animais que permaneceram no experimento, utilizou-se a relação PCVZ/PC média obtida nos animais-referência, dentro de cada classe sexual.

Ao término de cada abate, as carcaças foram transportadas para uma câmara frigorífica, onde foram resfriadas a $0^{\circ} \mathrm{C}$ por 18 a 24 horas. Transcorrido o resfriamento, as carcaças foram novamente pesadas, para determinação do rendimento de carcaça fria.

As variáveis estudadas foram analisadas estatisticamente por intermédio do programa MINITAB (1994), considerando-se classe sexual, nível de oferta de concentrado e a interação classe sexual $\times$ nível de oferta de concentrado como efeitos fixos. Adotou-se o nível de 5\% de probabilidade para as comparações entre as médias, que foram realizadas pelo teste Tukey.

\section{Resultados e Discussão}

A interação classe sexual $\times$ nível de oferta de concentrado não foi significativa $(\mathrm{P}>0,05)$ para nenhuma das variáveis estudadas. Desta forma, os efeitos de classe sexual e nível de oferta de concentrado foram avaliados e discutidos independentemente.

Os níveis de oferta de concentrado não se mostraram significativos $(\mathrm{P}>0,05)$ para consumo de MS $(\mathrm{g} / \mathrm{kg} \mathrm{PC})$, peso corporal final (PC final), peso de corpo vazio final (PCVZ final), ganhos médios de peso corporal (GMD), de carcaça ou de corpo vazio (GPCVZ), eficiência alimentar (EA) e eficiência de deposição de carcaça (Tabela 3). Silva et al. (2002) também não constataram efeito de níveis de concentrado sobre o consumo de MS, o desempenho e a conversão alimentar de tourinhos Nelore, corroborando os resultados obtidos neste estudo. Nesta pesquisa, o valor médio de consumo de MS para os dois níveis de oferta de concentrado foi de 20,15 g/kg PC. Silva et al. (2002), que 
Tabela 2 - Composição nutricional da silagem de milho, do milho moído fino, do farelo de algodão e das dietas experimentais

\begin{tabular}{|c|c|c|c|c|c|}
\hline Item & Silagem de milho & Fubá de milho & Farelo de algodão & \multicolumn{2}{|c|}{ Nível de concentrado $(\%)$} \\
\hline MS, \% & 24,34 & 87,13 & 87,02 & 40,25 & 55,95 \\
\hline $\mathrm{PB}, \% \mathrm{MS}$ & 6,17 & 9,07 & 46,87 & 12,06 & 12,10 \\
\hline $\mathrm{NIDN}, \% \mathrm{~N}$ total & 21,70 & 9,95 & 3,41 & 18,02 & 15,20 \\
\hline NIDA, \% do $\mathrm{N}$ total & 8,87 & 3,82 & 2,11 & 7,39 & 6,16 \\
\hline FDNp, \% MS & 59,16 & 11,53 & 30,35 & 48,60 & 36,35 \\
\hline $\mathrm{CNF}, \% \mathrm{MS}$ & 26,08 & 75,08 & 13,51 & 32,11 & 44,61 \\
\hline FDA, \% MS & 37,49 & 3,57 & 25,23 & 30,76 & 21,88 \\
\hline LIG, \% MS & 5,05 & 0,76 & 9,41 & 4,69 & 3,46 \\
\hline NDT, \% & - & - & - & 62,41 & 67,91 \\
\hline $\mathrm{ED}, \mathrm{Mcal} / \mathrm{kg} \mathrm{MS}$ & - & - & - & 2,72 & 2,95 \\
\hline
\end{tabular}

utilizaram níveis crescentes de inclusão de concentrado (20 a $80 \%$ da MS total da dieta), observaram consumo médio de MS de 18,10 g/kg PC. Percebe-se, portanto, que em ambas as situações os consumos de MS foram relativamente baixos, o que pode ter limitado a detecção de diferença significativa entre os tratamentos. Além disso, o consumo de proteína pelos animais nos dois níveis de oferta de concentrado foi semelhante (Tabela 4) e a diferença do conteúdo de energia da dieta total foi de apenas $8 \%$ (Tabela 2), fazendo com que os mecanismos físicos e fisiológicos de regulação do consumo atuassem de forma semelhante em todos os animais.

Por outro lado, classe sexual exerceu influência $(\mathrm{P}<0,05)$ sobre o ganho de peso, o consumo de MS (\% PC), a eficiência alimentar e a eficiência de deposição de carcaça dos animais (Tabela 3). Embora o efeito de sexo sobre a ingestão de alimentos ainda não esteja muito bem definido (ARC, 1980; NRC, 1987), o consumo de MS, relativo ao PC, foi superior nas fêmeas, em relação aos machos inteiros $(\mathrm{P}<0,05)$, ficando os machos castrados em posição intermediária. Ingvartsen et al. (1992) reportaram que novilhas com PC inferior a $250 \mathrm{~kg}$ apresentaram capacidade de consumo maior que machos inteiros e castrados. No entanto, em razão de as fêmeas apresentarem taxa de maturação mais pronunciada que machos castrados e estes, por sua vez, mais que machos inteiros, com concomitante maior acúmulo de gordura corporal, esperar-se-ia que a capacidade de consumo das fêmeas diminuísse com o aumento do PC, uma vez que a gordura exerce influência direta, por limitações físicas impostas pela gordura abdominal sobre o rúmen, e indiretas sobre a ingestão alimentar, pela secreção de leptina pelos adipócitos, hormônio que tem sido correlacionado a reduções no consumo (Nkrumah et al., 2005). No entanto, até o ponto em que os animais foram abatidos, não houve efeito, provavelmente, porque as fêmeas ainda não tinham atingido conteúdo corporal de gordura suficiente para desencadear reduções na ingestão alimentar.

Alguns relatos presentes no NRC (1987) atestaram situações em que o consumo de MS observado em novilhas foi similar (Fox et al., 1984) ou superior (Klosterman \& Parker, 1976) em 3 a 5\% aos consumos observados em machos castrados e inteiros. Ayala (1974), citado pelo NRC (1987), encontrou consumos relativos similares entre machos inteiros, castrados e fêmeas. Desta forma, o efeito de sexo propriamente dito parece não ser muito consistente sobre o consumo de MS em bovinos de corte, sendo seus efeitos confundidos com outros fatores, como peso corporal, idade e composição corporal. Porém, uma possível explicação para o maior consumo relativo de MS observado para as fêmeas pode ser seu menor peso corporal (Tabela 3), visto que animais mais leves tendem a apresentar capacidade de consumo superior a animais mais pesados. Isso ocorre porque o tamanho do aparelho gastrintestinal está relacionado proporcionalmente ao peso corporal (expoente igual a 1), enquanto as exigências de energia, ao peso corporal elevado à potência 0,75 (Van Soest, 1994). Como o consumo depende desses dois fatores, o melhor expoente para descrever o consumo em função do PC encontrar-se-ia entre esses dois valores, em torno de $0,5 \mathrm{e}$ 0,8 (Colburn \& Evans, 1968). Expoentes inferiores a 1 implicam que o consumo de MS, em relação ao PC, decresce de forma mais intensa, à medida que o peso se eleva. Desta forma, parece que ocorre maior turnover do conteúdo ruminal em animais com pesos mais leves (NRC, 1987).

Os machos inteiros foram mais pesados $(\mathrm{P}<0,05)$ que as fêmeas ao final do experimento, ficando os castrados em posição intermediária (Tabela 3). Essa observação reflete, pelo menos em parte, as diferenças detectadas entre os 
Tabela 3 - Peso corporal final (PC final), peso de corpo vazio final (PCVZ final), consumo de matéria seca (CMS), ganho médio diário (GMD), ganho de peso de corpo vazio (GPCVZ), eficiência alimentar (EA), ganho de carcaça e eficiência de deposição de carcaça de bovinos Nelore de diferentes classes sexuais (CS), alimentados com dois níveis de oferta de concentrado (NC) na dieta

\begin{tabular}{|c|c|c|c|c|c|c|c|c|}
\hline Item & \multicolumn{3}{|c|}{ Classe sexual } & \multicolumn{2}{|c|}{ Nível de oferta de concentrado } & \multicolumn{3}{|c|}{ Valor P } \\
\hline $\mathrm{PC}$ final, $\mathrm{kg}$ & $435,0 \mathrm{a}$ & $396,0 \mathrm{ab}$ & $372,0 \mathrm{~b}$ & 407,5 & 394,2 & 0,003 & 0,307 & 0,726 \\
\hline CMS, g/kg de PV & $19,3 \mathrm{~b}$ & $20,0 \mathrm{ab}$ & $21,1 \mathrm{a}$ & 20,0 & 20,3 & 0,018 & 0,399 & 0,567 \\
\hline GMD, $\mathrm{kg} / \mathrm{dia}$ & $0,83 \mathrm{a}$ & $0,69 b$ & $0,66 \mathrm{~b}$ & 0,74 & 0,71 & 0,048 & 0,665 & 0,280 \\
\hline GPCVZ, kg/dia & $0,92 \mathrm{a}$ & $0,76 \mathrm{ab}$ & $0,69 b$ & 0,77 & 0,80 & 0,003 & 0,494 & 0,155 \\
\hline Ganho de carcaça, $\mathrm{kg} / \mathrm{dia}$ & $0,58 \mathrm{a}$ & $0,47 \mathrm{ab}$ & $0,44 b$ & 0,49 & 0,51 & 0,010 & 0,619 & 0,329 \\
\hline Eficiência de deposição de carcaça ${ }^{1}$ & $a^{1} \quad 13,20 b$ & $15,91 \mathrm{ab}$ & $16,64 \mathrm{a}$ & 15,86 & 14,63 & 0,012 & 0,179 & 0,305 \\
\hline
\end{tabular}

Médias, na mesma linha, dentro de classe sexual ou nível de concentrado, seguidas por letras diferentes, diferem entre si $(P<0,05)$

$1 \mathrm{~kg}$ de MS consumida/kg de ganho de carcaça;

grupos sexuais para o ganho médio diário de peso de corpo vazio e de carcaça (Tabela 3). Silva et al. (2005) também verificaram que o PC final de machos inteiros Nelore $x$ Piemontês foi superior ao das fêmeas, após 131 dias de confinamento. Machos inteiros apresentaram desempenho em ganho médio diário $18,7 \%$ superior à média dos machos castrados e das fêmeas, ganharam $17,4 \%$ mais peso de corpo vazio e $21,6 \%$ mais carcaça que a média dos machos castrados e das fêmeas (Tabela 3), concordando com relatos da literatura de que animais inteiros crescem a uma taxa cerca de 10-25\% maior que a obtida nos animais castrados (Purchas et al., 2002; Padua et al., 2004). Junqueira et al. (1998) também detectaram que machos inteiros tiveram ganho de peso médio diário superior que as fêmeas de mesma idade (1,44 vs $1,18 \mathrm{~kg} / \mathrm{dia})$.

Com relação à eficiência alimentar, é sabido que machos inteiros apresentam melhor capacidade de converter alimentos em ganho de peso e em tecidos componentes da carcaça (Seideman et al., 1982). Os animais inteiros obtiveram taxas mais pronunciadas de ganho de carcaça, depositando mais carcaça e apresentando maior ganho em peso, para cada quilo de MS consumida, que as fêmeas $(\mathrm{P}<0,05)$, ficando os castrados em posição intermediária (Tabela 3). As fêmeas, além de terem apresentado maior consumo, quando expresso em $\%$ do PC, que os animais inteiros, também cresceram de forma mais lenta $(0,83 \times 0,66 \mathrm{~kg} / \mathrm{dia})$, resultando, portanto, em menor eficiência alimentar e de deposição de carcaça. O ranqueamento observado para o desempenho e a eficiência alimentar, com os machos inteiros se destacando em relação às fêmeas e os machos castrados se situando em posição intermediária, está de acordo com revisão extensa realizada por Purchas (1991), acerca do efeito de sexo sobre o crescimento e a composição corporal e da carcaça de bovinos de corte. Marion et al. (1980) não detectaram diferença no ganho médio diário e na eficiência alimentar entre machos castrados e novilhas, corroborando os dados obtidos neste experimento.

O consumo de todos os nutrientes, quando expressos em termos absolutos ( $\mathrm{kg} / \mathrm{dia})$, não foram afetados $(\mathrm{P}>0,05)$ pela classe sexual (Tabela 4). Já o efeito do nível de oferta de concentrado mostrou-se significativo para os consumos de FDN e CNF $(\mathrm{P}<0,05)$, sendo que os animais alimentados com a dieta cuja oferta de concentrado foi de $0,6 \%$ PC apresentaram maiores $(\mathrm{P}<0,05)$ consumos de FDN e, conseqüentemente, menores consumos de $\mathrm{CNF}(\mathrm{P}<0,05)$, quando comparados aos animais que receberam $1,2 \% \mathrm{PC}$ em concentrado (Tabela 4). Esse efeito se deve ao fato de os animais que receberam menor quantidade de concentrado $(0,6 \%$ PC) terem ingerido uma dieta com maior participação de volumoso, cuja concentração de fibra na MS $(60,87 \%$ de FDN) foi bem superior à do concentrado (17,98 e 14,49\%, respectivamente, para os concentrados ofertados a $0,6 \mathrm{e}$ $1,2 \%$ do PC). A dieta dos animais com oferta de concentrado de 1,2\% PC apresentou relação volumoso:concentrado em torno de 50:50, o que permitiu maior ingestão de CNF, oriundos do concentrado, e menor consumo de FDN. Houve maior consumo de NDT $(\mathrm{P}<0,05)$, quando expresso em função do peso corporal, para os animais que receberam $1,2 \%$ PC em concentrado (Tabela 4) em relação aos que receberam a menor quantidade de concentrado. Como as dietas foram formuladas de forma a serem isoprotéicas ( $12 \%$ de PB) e o consumo de MS foi semelhante entre as duas dietas (Tabela 3), não se verificou efeito $(\mathrm{P}>0,05)$ do nível de concentrado sobre os consumos de PB. Quando os consumos foram analisados de forma relativa ao peso corporal médio, verificou-se que as fêmeas apresentaram consumos superiores ao dos machos inteiros $(\mathrm{P}<0,05)$, ficando os machos castrados em posição intermediária (Tabela 4). Consumos de EE, CNF e de energia (NDT e EM) foram superiores 
Tabela 4 - Consumos médios de MO, PB, EE, FDN, CNF, NDT e EM de bovinos Nelore de diferentes classes sexuais (CS), alimentados com dois níveis de oferta de concentrado (NC) na dieta

\begin{tabular}{|c|c|c|c|c|c|c|c|c|}
\hline \multirow[t]{2}{*}{ Item } & \multicolumn{3}{|c|}{ Classe sexual } & \multicolumn{2}{|c|}{ Nível de oferta de concentrado } & \multicolumn{3}{|c|}{ Valor P } \\
\hline & Machos inteiros & Machos castrados & Fêmeas & $0,6 \% \mathrm{PC}$ & $1,2 \% \mathrm{PC}$ & CS & $\mathrm{NC}$ & INT \\
\hline \multicolumn{9}{|c|}{ Consumo, kg/dia } \\
\hline $\mathrm{MO}^{1}$ & 7,16 & 6,93 & 6,81 & 7,05 & 6,88 & 0,505 & 0,511 & 0,573 \\
\hline $\mathrm{PB}^{2}$ & 0,90 & 0,88 & 0,85 & 0,90 & 0,85 & 0,374 & 0,163 & 0,568 \\
\hline $\mathrm{EE}^{2}$ & 0,24 & 0,24 & 0,23 & 0,23 & 0,24 & 0,353 & 0,545 & 0,677 \\
\hline $\mathrm{FDN}^{1}$ & 3,27 & 3,16 & 3,13 & $3,64 \mathrm{a}$ & $2,73 b$ & 0,557 & $<0,0001$ & 0,409 \\
\hline $\mathrm{CNF}^{1}$ & 2,95 & 2,86 & 2,80 & $2,48 b$ & $3,26 \mathrm{a}$ & 0,522 & $<0,0001$ & 0,730 \\
\hline $\mathrm{NDT}^{1}$ & 4,89 & 4,77 & 4,71 & 4,65 & 4,93 & 0,640 & 0,083 & 0,303 \\
\hline \multicolumn{9}{|c|}{ Consumo, \% PC } \\
\hline MO & $1,83 \mathrm{~b}$ & $1,89 \mathrm{ab}$ & $2,00 \mathrm{a}$ & 1,89 & 1,93 & 0,017 & 0,344 & 0,573 \\
\hline $\mathrm{PB}$ & $0,23 b$ & $0,24 a b$ & $0,25 \mathrm{a}$ & 0,24 & 0,24 & 0,047 & 0,665 & 0,643 \\
\hline $\mathrm{EE}$ & $0,063 \mathrm{~b}$ & $0,065 \mathrm{ab}$ & $0,068 \mathrm{a}$ & $0,063 b$ & $0,06 \mathrm{a}$ & 0,004 & 0,002 & 0,742 \\
\hline FDN & $0,84 \mathrm{~b}$ & $0,86 \mathrm{ab}$ & $0,92 \mathrm{a}$ & $0,98 \mathrm{a}$ & $0,77 b$ & 0,005 & $<0,0001$ & 0,772 \\
\hline $\mathrm{CNF}$ & $0,76 \mathrm{~b}$ & $0,79 \mathrm{ab}$ & $0,82 \mathrm{a}$ & $0,67 \mathrm{~b}$ & $0,91 \mathrm{a}$ & 0,050 & $<0,0001$ & 0,382 \\
\hline NDT & $1,26 \mathrm{~b}$ & $1,31 \mathrm{ab}$ & $1,39 \mathrm{a}$ & $1,24 b$ & $1,39 \mathrm{a}$ & 0,004 & $<0,0001$ & 0,148 \\
\hline \multicolumn{9}{|c|}{ Consumo, Kcal//kg $\mathrm{PC}^{0,75}$} \\
\hline EM & 198,70 & 203,61 & 211,97 & $195,33 \mathrm{~b}$ & $214,19 \mathrm{a}$ & 0,082 & 0,001 & 0,161 \\
\hline
\end{tabular}

Médias, na mesma linha, dentro de classe sexual ou nível de concentrado, seguidas por letras diferentes, diferem $(P<0,05)$ entre si.

$1 \mathrm{~kg} / \mathrm{dia} ;{ }^{2} \mathrm{~g} / \mathrm{dia}$.

Tabela 5 - Coeficientes de digestibilidade aparente total de MS, MO, PB, EE, FDN e CNF em bovinos Nelore de diferentes classes sexuais, alimentados com dois níveis de oferta de concentrado (NC) na dieta

\begin{tabular}{|c|c|c|c|c|c|c|c|c|}
\hline Item & \multicolumn{3}{|c|}{ Classe sexual } & \multicolumn{2}{|c|}{ Nível de oferta de concentrado } & \multicolumn{3}{|c|}{ Valor P } \\
\hline \multicolumn{9}{|c|}{ Coeficiente de digestibilidade aparente total, $\%$} \\
\hline MS & 59,32 & 59,53 & 59,35 & $56,22 \mathrm{~b}$ & $62,58 \mathrm{a}$ & 0,975 & $<0,0001$ & 0,467 \\
\hline MO & 62,31 & 62,83 & 63,02 & $59,78 \mathrm{~b}$ & $65,66 a$ & 0,790 & $<0,0001$ & 0,453 \\
\hline $\mathrm{PB}$ & 58,67 & 58,59 & 58,76 & 57,91 & 59,43 & 0,992 & 0,181 & 0,297 \\
\hline $\mathrm{CNF}$ & 86,79 & 87,11 & 86,42 & 86,34 & 87,20 & 0,812 & 0,336 & 0,240 \\
\hline
\end{tabular}

Médias, na mesma linha, dentro de classe sexual ou nível de concentrado, seguidas por letras diferentes, diferem $(P<0,05)$ entre si.

$(\mathrm{P}<0,05)$ nos animais do tratamento em que o nível ofertado de concentrado foi de $1,2 \%$ do PC, enquanto o consumo de FDN foi inferior $(\mathrm{P}<0,05)$.

Verificou-se que somente a digestibilidade aparente total do EE foi afetada $(\mathrm{P}<0,05)$ pela classe sexual (Tabela 5). A digestibilidade aparente dos demais nutrientes, dentro das três classes sexuais, foram estatisticamente semelhantes $(\mathrm{P}>0,05)$. O nível de oferta de concentrado afetou somente as digestibilidades aparentes totais de MS e MO, que foram aproximadamente $10 \%$ superiores $(\mathrm{P}<0,05)$ para os animais alimentados com a maior quantidade de concentrado. Essa melhora na digestibilidade parece ser reflexo da maior ingestão de CNF provenientes do concentrado no tratamento com oferta de concentrado de 1,2\% PC. Ítavo et al. (2002) também não detectaram efeitos de níveis de concentrado sobre as digestibilidades de EE e PB, como observado neste trabalho. É interessante notar que, apesar de as digestibilidades da MS e MO terem sido superiores no tratamento com $1,2 \%$ PC em concentrado, nenhum outro nutriente teve sua digestibilidade afetada, denotando que a digestibilidade total de uma dieta é o saldo dos efeitos interativos e associativos de todos os nutrientes da dieta, e não do efeito isolado de determinado constituinte. Mesmo no nível mais alto de oferta de concentrado, a digestibilidade da porção fibrosa da dieta não foi afetada, provavelmente devido à obtenção do balanceamento entre o total da proteína dietética degradável no rúmen e o teor de energia da dieta, uma vez que essa associação 
ajuda a manter a digestão da fibra, mesmo em situações em que suplementos ricos em amido são fornecidos aos animais (Bodine et al., 2001).

\section{Conclusões}

Classe sexual representa um fator determinante no crescimento de animais da raça Nelore

Fêmeas jovens da raça Nelore apresentam capacidade de consumo superior aos machos.

A classe sexual de bovinos Nelore não influencia as digestibilidades de MS e dos demais nutrientes dietéticos, com exceção do EE.

A interação classe sexual $\times$ nível de oferta de concentrado parece não afetar o desempenho, o consumo e a digestibilidade em bovinos Nelore consumindo até $1,2 \%$ do peso corporal em concentrado.

\section{Agradecimento}

Aos funcionários do Laboratório Animal e do Laboratório de Nutrição Animal do Departamento de Zootecnia da Universidade Federal de Viçosa, pelo apoio e auxílio durante a execução do experimento. Aos estagiários e bolsistas que dedicaram e proporcionaram cooperação indispensável à realização deste trabalho.

\section{Literatura Citada}

AGRICULTURAL RESEARCH COUNCIL - ARC. The nutrient requirements of ruminants livestock. London: CAB, 1980. $351 \mathrm{p}$.

BERG, R.T.; BUTTERFIELD, R.M. New concepts of cattle growth. 1.ed. Sydney: Sydney University Press, 1976. 240p.

BODINE, T.N.; PURVIS II, H.T.; LALMAN, D.L. Effects of supplement type on animal performance, forage intake, digestion, and ruminal measurements of growing beef cattle. Journal of Animal Science, v.79, n.4, p.1041-1051, 2001.

COCHRAN, R.C.; ADAMS, D.C.; WALLACE, J.D. et al. Predicting digestibility of different diets with internal markers: evaluation of four potential markers. Journal of Animal Science, v.63, n.5, p.1476-1483, 1986.

COLBURN, M.W.; EVANS, J.L. Reference base, $\mathrm{W}^{\mathrm{b}}$, of growing steers determined by relating forage intake to body weight. Journal of Dairy Science, v.51, p.1073-1079, 1968.

FORTIN, A.; SIMPFENDORFER, S.; REID, J.T. et al. Effect of level of energy intake and influence of breed and sex on the chemical composition of cattle. Journal of Animal Science, v.51, n.3, p.604-614, 1980.

FOX, D.G.; SNIFFEN, C.J.; Van SOEST, P.J. A net protein system for cattle. In: GEORGIA NUTRITION CONFERENCE, 1984, Atlanta. Proceedings... Atlanta: University of Georgia, 1984. p.1-20.

HALL, M.B. Calculation of non-structural carbohydrate content of feeds that contain non-protein nitrogen. Gainesville: University of Florida, 2000. p.A-25 (Bulletin, 339).
INGVARTSEN, K.L.; ANDERSEN, H.R.; FOLDAGER, J. Effect of sex and pregnancy on feed intake capacity of growing cattle. Acta Agriculture Scandinavia, v.42, p.40-46, 1992.

ÍTAVO, L.C.V.; VALADARES FILHO, S.C.; SILVA, F.F. et al. Consumo e digestibilidades aparentes totais e parciais de nutrientes em novilhos alimentados com dietas contendo vários níveis de concentrado. Revista Brasileira de Zootecnia, v.31, n.1, p.1543-1552, 2002.

JUNQUEIRA, J.O.B.; VELLOSO, L.; FELÍCIO, P.E. Desempenho, rendimentos de carcaça e cortes de animais, machos e fêmeas, mestiços Marchigiana $\mathrm{x}$ Nelore, terminados em confinamento. Revista Brasileira de Zootecnia, v.27, n.6, p.1199-1205, 1998

KLOSTERMAN, E.W.; PARKER, C.F. Effect of size, breed and sex upon efficiency in beef cattle. Ohio Research Bulletin, v. $1088,1976.26 \mathrm{p}$.

LICITRA, G.; HERNANDEZ, T.M.; VAN SOEST, P.J. Standardization of procedures for nitrogen fractionation of ruminant feeds. Animal Feed Science and Technology, v.57, n.4, p.347-358, 1996.

MARION, W.F.; DIKERMAN, M.E.; DAYTON, A.D. Performance and composition of steers and heifers of two biological types related to net energy for production efficiency. Journal of Animal Science, v.51, n.4, p.882-891, 1980.

MINITAB. Minitab Reference Manual. Release 10 for Windows. Minitab Statistical Software. State College: 1994.

NATIONAL RESEARCH COUNCIL - NRC. Nutrient requirements of beef cattle. 7.rev.ed. Washington, D.C.: National Academic Press, 2000. 242p.

NATIONAL RESEARCH COUNCIL - NRC. Nutrient requirements of dairy cattle. 7.ed. Washington, D.C.: National Academic Press, 2001. 381p.

NATIONAL RESEARCH COUNCIL - NRC. Predicting feed intake of food-producing animals. 7.rev.ed. Washington, D.C.: National Academic Press, 1987. 85p.

NKRUMAH, J.D.; LI, C.; YU, J. et al. Polymorphisms in the bovine leptin promoter associated with serum leptin concentration, growth, feed intake, feeding behaviour, and measures of carcass merit. Journal of Animal Science, v.83, n.1, p.20-28, 2005

PADUA, J.T.; MAGNABOSCO, C.U.; SAINZ, R.D. et al. Genótipo e condição sexual no desempenho e nas características de carcaça de bovinos de corte superjovens. Revista Brasileira de Zootecnia, v.33, n.6, p.2330-2342, 2004 (supl. 3).

PAULINO, P.V.R.; VALADARES FILHO, S.C.; DETMANN, E. et al. Consumo residual, performance e características de carcaça de bovinos Nelore de diferentes classes sexuais. In: CONGRESSO BRASILEIRO DAS RAÇAS ZEBUÍNAS, 6., 2005, Uberaba. Anais... Uberaba: Associação Brasileira dos Criadores de Zebu, 2005. p.304-307.

PEREIRA, D.H.; PEREIRA, O.G.; VALADARES FILHO, S.C. et al. Consumo, digestibilidade dos nutrientes e desempenho de bovinos de corte recebendo silagem de sorgo (Sorghum bicolor (L.) Moench) e diferentes proporções de concentrado. Revista Brasileira de Zootecnia, v.35, n.1, p.282-291, 2006.

POLAQUINI, L.E.M.; SOUZA, J.G.; GEBARA, J.J. Transformações técnico-produtivas e comerciais na pecuária de corte brasileira a partir da década de 90 . Revista Brasileira de Zootecnia, v.35, n.1, p.321-327, 2006.

PURCHAS, R.W.; BURNHAM, D.L.; MORRIS, S.T. Effects of growth potential and growth path on tenderness of beef longissimus muscle from bulls and steers. Journal of Animal Science, v. 80, p.3211-3221, 2002.

PURCHAS, R.W. Effect of sex and castration on growth and composition. In: PEARSON, A.M.; DUTSON, T.R. (Eds.). Growth regulation in farm animals - advances in meat research. 1.ed. London: 1991. p.203-254.

SEIDEMAN, S.C.; CROSS, H.R.; OLTJEN, R.R. et al. Utilization of the intact male for red meat production: a review. Journal of Animal Science, v.55, n.4, p.826-840, 1982. 
SILVA, D,J.; QUEIROZ, A.C. Análise de alimentos (Métodos químicos e biológicos). 3.ed. Viçosa, MG: Editora UFV, 2002. 235p.

SILVA, F.F.; VALADARES FILHO, S.C.; ÍTAVO, L.C.V. et al. Consumo, desempenho, características de carcaça e biometria do trato gastrintestinal e dos órgãos internos de novilhos Nelore recebendo dietas com diferentes níveis de concentrado e proteína. Revista Brasileira de Zootecnia, v.31, n.4, p. 1849-1864, 2002.

SILVA, S.L.; TITTO, E.A.L.; LEME, P.R. et al. Days on feed and sex effects on live weight and carcass traits measured by ultrasound. Scientia Agricola, v.62, n.5, p.423-426, 2005.
Van SOEST, P.J. Nutritional ecology of the ruminant. 2.ed. Ithaca: Cornell University Press, 1994. 476p.

Van SOEST, P.J.; ROBERTSON, J.B. Systems of analysis for evaluating fibrous feeds. In: PIGDEN, W.J.; BALCH, C.C.; GRAHAM, M. (Eds.) Standardization of analytical methodology for feeds. 1.ed. Ottawa: International Development Research Centre, 1980. p.49.

Van SOEST, P.J.; ROBERTSON, J.B.; LEWIS, B.A. Methods for dietary fiber, neutral detergent fiber, and nonstarch polyssacarides in relation to animal nutrition. Journal of Animal Science, v.74, n.10, p.3583-3597, 1991. 